\title{
Inocencia Interrumpida: La Protección de los Derechos Fundamentales de los Niños y Adolescentes a Propósito del Caso VRAEM
}

\author{
Interrupted Innocence: The protection of fundamental rights of \\ children and adolescents in relation to VRAEM case
}

Karen Maribel Rebaza Vilchez*

\section{Resumen}

En el presente articulo la autora identifica-desde una perspectiva constitucional y de derecho internacional - el Bloque de Constitucionalidad en materia de protección de niños y adolescentes víctimas de reclutamiento por grupos irregulares, a fin de sustentar la necesidad de promulgación de normas en el ordenamiento jurídico interno que protejan los derechos de este grupo vulnerable y se evite, a su vez, una posible imputación de responsabilidad internacional al Estado peruano por incumplir con sus obligaciones internacionales al respecto.

\section{Palabras clave}

Bloque de constitucionalidad, Derechos fundamentales, Enfrentamientos armados, Instrumentos internacionales, Niños y adolescentes, Omisión legislativa, Responsabilidad internacional del Estado.

\begin{abstract}
In this article the author identifies - from a international law and constitutional perspective - the Block of Constitutionality concerning the protection of children and adolescents victims of recruitment by rebel groups, in order to sustain the need of promulgation of rules in the internal legal system to protect the rights of this vulnerable group and to avoid, at the same time, a possible imputation of international responsibility to the Peruvian State for failing with his respective international obligations.
\end{abstract}

\footnotetext{
* Abogada por la Universidad Femenina del Sagrado Corazón (UNIFE). Asistente Legal de la Dirección de Derechos Humanos del Ministerio de Relaciones Exteriores del Perú.
}

Fecha de recepción: 20/07/2014

Fecha de aceptación: 23/09/2014 


\section{Keys words:}

Block of Constitutionality, Fundamental Rights, Armed clashes, International instruments, Children and adolescents, Legislative omission, International Responsibility of the State.

\section{Introducción:}

El 28 de mayo del año 2003, mediante Decreto Supremo Nº 055-2003PCM, se declaró el Estado de Emergencia en todo el territorio nacional por un plazo de 30 días. Mediante un mensaje a la Nación, el ex Presidente Alejandro Toledo Manrique encargó a la Policía Nacional y a las Fuerzas Armadas el control del orden interno debido a la ola de protestas que acontecían en nuestro país.

Posteriormente, en fecha 26 de junio del mismo año, mediante Decreto Supremo $N^{\circ}$ 062-2003-PCM, dieron por concluido el Estado de Emergencia a nivel nacional; sin embargo, prorrogaron la declaratoria en los departamentos de Junín, Ayacucho, Apurímac y la provincia de La Convención del departamento de Cusco.

Al finalizar esa prórroga, el 25 de julio de 2003, mediante Decreto Supremo No 070-2003-PCM, se volvió a decretar el Estado de Emergencia en los citados territorios e incluyeron a la provincia de Tayacaja del departamento de Huancavelica.

Lamentablemente, a partir de esa fecha, se ha mantenido dicha tendencia; diferentes provincias de esos departamentos viven en permanente Estado de Emergencia; tal es así que muchos de esos territorios son los que actualmente conforman la zona con mayor preocupación en materia de seguridad a nivel nacional: el VRAEM.

Como se puede apreciar de la información que circula por los medios de comunicación, el Valle del Río Apurímac, Ene y Mantaro, más conocida por sus siglas VRAEM, se caracteriza por sus elevados niveles de pobreza y por la producción cocalera dirigida fundamentalmente al narcotráfico. Esto último ha traído consigo, según opinión del señor Jaime Antezana, conocido experto peruano en temas de narcotráfico, la participación de remanentes de Sendero Luminoso, que aún se encuentran anclados en esa zona, en la cadena misma de producción, traslado y comercialización de drogas; por lo que ahora, en buena cuenta, son denominados "narcoterroristas". 
Entonces, si bien el Sendero Luminoso del VRAEM no es el Sendero Luminoso de nuestro pasado, es un grupo armado insurgente inmerso en lucrativas actividades económicas, cuya estructura y dinámica organizativa no se agotan en su relación con el narcotráfico al tener sus actividades aún una fuerte connotación política.

En ese sentido, la situación que se vive en esta zona es preocupante sobretodo porque los niños y adolescentes no son ajenos a los enfrentamientos armados que se suscitan.

En los últimos años, estos grupos están empleando niños y adolescentes en sus actividades violentas y subversivas en contra de la fuerza pública que opera en dicha zona, ya que en el VRAEM, como señala Eduardo Toche, los niños reclutados representan la esperanza del partido, ya que en su visión de "guerra prolongada" son vistos como "la reserva humana" que reemplazaría a quienes cayeran en combate. ${ }^{1}$

Entonces, teniendo en cuenta: 1) el carácter organizado y jerárquico de estos grupos;2) que en este territorio las declaratorias de Estado de Emergencia son continuas; $\mathrm{y}, 3$ ) que los enfrentamientos armados entre el Ejército y los remanentes de Sendero son recurrentes, el Estado peruano debe estar preparado para enfrentar este flagelo a los derechos de la niñez y adolescencia mediante un tratamiento jurídico diferenciado y especial que deberá seguir la línea de los diferentes instrumentos internacionales ratificados por el Perú en la materia.

Dentro este orden de ideas, a continuación desarrollaré los puntos más relevantes del tema en cuestión.

\section{Niños y Adolescentes involucrados en enfrentamientos armados en el VRAEM}

Dada las dificultades geográficas y de seguridad existentes en las principales provincias y distritos que conforman el VRAEM, el estudio de los fenómenos ilegales ocurridos en estos territorios, como objeto de investigación jurídica, son relativamente recientes.

\footnotetext{
${ }^{1}$ Toche Medrano, Eduardo. Op. Cit.p. 45.
} 
Sin embargo, para tener un panorama amplio sobre esta zona es importante señalar que tiene aproximadamente 388,890 habitantes con un predominio de niños y adolescentes, que constituyen el $42 \%$ del total ${ }^{2}$. Asimismo, se encuentra a la fecha, según lo señalado por el actual Ministro de Defensa, Pedro Cateriano, con 45 bases militares.

La participación de menores en enfrentamientos armados en el VRAEM, se ha corroborado por distintos medios, entre los cuales me permito señalar los siguientes:

-Audiencia ante la Comisión Interamericana de Derechos Humanos: "Utilización de niños en organizaciones armadas y reclutamiento de menores en las fuerzas armadas peruanas"

El 23 de marzo de 2010, en el marco de su $138^{\circ}$ periodo de sesiones, la Comisión Interamericana de Derechos Humanos, representada por su entonces Vicepresidente, Sr. Paulo Sergio Pinheiro, recibió en la ciudad de Washington como Peticionarios a la "Coordinadora Nacional de Derechos humanos" conjuntamente con Save the Children, representados por la señora Ana María Tamayo; y como integrantes de la Delegación peruana, a la Dra. Delia Muñoz, ex Procuradora Supranacional, el Dr. Javier Villa- Stein, Presidente del Poder Judicial, el Dr. Víctor Cubas, Fiscal Superior del Ministerio Público y el Dr. Luis Cobeñas, como representante del Ministerio de Defensa.

Dicha audiencia tuvo como objeto poner en conocimiento de la Comisión Interamericana la situación de vulneración de los derechos del niño en el Perú a raíz de su empleo por parte de la organización terrorista Sendero Luminoso en ataques armados, así como los casos de reclutamiento ilegal de menores de edad en el servicio militar voluntario por parte de las fuerzas armadas peruanas.

En el desarrollo del encuentro, en relación al reclutamiento de niños y adolescentes por Sendero Luminoso, se indicó que en el VRAEM sus derechos están siendo altamente vulnerados y respecto de éstos se han formado poca conciencia pública en el país.

${ }^{2}$ Novak, Fabián \& Namihas, Sandra \& García-Corrochano, Luis \& Huamán, Milagros. Op. Cit. p.17 
Asimismo, señalaron que la Organización terrorista Senderista Luminoso apostada en zonas estratégicas del VRAEM, continúan empleando niños y adolescentes en sus ataques armados como lo hizo en la década de los $80^{\prime}$ y $90^{\prime}$. Describieron que los medios de comunicación nacional en el Perú han reproducido durante el año 2009 entrevistas a soldados del ejército peruano que así lo denuncian y también han transmitido imágenes a la opinión pública en las que se muestra a niños y adolescentes manipulando armas de guerra, entonando cánticos y arengas.

Al finalizar su intervención, la Coordinadora Nacional de Derechos Humanos y Save the Children pidieron a la Comisión Interamericana, entre otras cosas, que solicite al Estado peruano adoptar todas las medidas jurídicas, administrativas, y de otra índole necesarias para garantizar la erradicación del reclutamiento de los niños, niñas y adolescentes por Sendero Luminoso.

Por su parte, la Delegación peruana suscribió lo suscitado con Sendero Luminoso y su accionar en el VRAEM, y reconoció la necesidad de adecuar las leyes internacionalmente en materia de reclutamiento de niños $y$ adolescentes.

-Revista "Comando en Acción", Órgano oficial de información del Comando Conjunto de las Fuerzas Armadas del Perú

La Revista "Comando en Acción" en su edición N 52-2012 titulada "Salvados del infierno" y publicada en el año 2012, abarca como temática la situación de los niños soldados en diferentes partes del mundo y de nuestro país.

En esa edición, se hace un análisis de los testimonios de niños que han huido del VRAEM, asimismo, integran entrevistas a psicólogos que hacen referencia a la necesidad urgente de que estos niños pasen por un tratamiento psicológico especial ya que al estar expuestos a abusos físicos y psicológicos, las consecuencias podrían ser devastadoras de no ser tratadas de forma oportuna.

Asimismo, se indica que mediante la "Operación Albergue", ejecutada en julio de 2012 por el Comando Conjunto de las Fuerzas Armadas con la Policía Antidrogas, se rescató once niños y capturó once remanentes de Sendero Luminoso en el poblado de Sanal, distrito de San Martín de Pangoa, 
en la provincia de Satipo; sin embargo, dan a conocer con pesar que la población de niños víctimas de reclutamiento es superior a las dos centenas.

Todo este escenario, lleva a considerar que la militarización del VRAEM trae un peligro real y la situación de vulnerabilidad del creciente número de niños y adolescentes que participan en los enfrentamientos armados es sumamente alarmante. El Estado peruano además de encontrarse obligado a adoptar todas las medidas necesarias para rescatar a estos niños y adolescentes a efectos de rehabilitarlos e integrarlos a la sociedad, tiene como tarea primordial evitar la impunidad de sus responsables y cumplir con sus obligaciones internacionales al respecto.

3. Bloque de Constitucionalidad en materia de Protección de los Derechos Fundamentales de los niños y adolescentes víctimas de reclutamiento

\begin{tabular}{|c|c|}
\hline SISTEMA UNIVERSAL DE DERECHOS HUMANOS & $\begin{array}{l}\text { SISTEMA } \\
\text { INTERAMERICANO DE } \\
\text { DERECHOS HUMANOS }\end{array}$ \\
\hline $\begin{array}{l}\text { - Declaración Universal de Derechos Humanos: Artículo } 25^{\circ} \text {. } \\
\text { - Declaración de los Derechos del Niño: Segundo Principio, } \\
\text { Octavo Principio, Noveno Principio. } \\
\text { - Pacto Internacional de Derechos Civiles y Políticos: Artículo } 24^{\circ} \text {. } \\
\text { - Convenio } 182 \text { de la Organización Internacional del Trabajo (OIT) } \\
\text { relativa a las Peores Formas de Trabajo Infantil y la Acción } \\
\text { Inmediata para su Eliminación: Artículo } 3^{\circ} \text {. } \\
\text { - Recomendación } 190 \text { de la OIT sobre la Prohibición de las } \\
\text { Peores Formas de Trabajo Infantil después de haber adoptado } \\
\text { el Convenio sobre las peores formas de Trabajo Infantil: Punto } \\
\text { once y doce. } \\
\text { - Convención sobre los Derechos del Niño: Articulo } 38^{\circ} \text { y } 39^{\circ} \text {. } \\
\text { - Protocolo Facultativo de la Convención sobre los Derechos del } \\
\text { Niño relativo a la participación de los niños en conflictos } \\
\text { armados: Artículo } 4^{\circ}, 6^{\circ} \text { y } 7^{\circ} \text {. }\end{array}$ & $\begin{array}{l}\text { - Declaración Americana } \\
\text { de Derechos y Deberes } \\
\text { del Hombre: Artículo VIl. } \\
\text { - Convención Americana } \\
\text { sobre Derechos Humanos: } \\
\text { Artículo } 19^{\circ} \text {. } \\
\text { - Protocolo Adicional a la } \\
\text { Convención American } \\
\text { sobre Derechos Humanos: } \\
\text { Artículo } 16^{\circ} \text {. }\end{array}$ \\
\hline
\end{tabular}


Para probar si se ha dado una omisión, inercia o pasividad de producción normativa referente a la protección de los derechos fundamentales de los niños y adolescentes víctimas de reclutamiento por grupos irregulares, la herramienta más eficaz es el "Bloque de Constitucionalidad".

El Bloque de Constitucionalidad opera como un conjunto de disposiciones básicas que deben regular la producción de las demás normas de rango inferior del ordenamiento jurídico interno. Este instrumento está integrado por disposiciones constitucionales y por tratados en materia de derechos humanos; en ese sentido, en su uso para el presente contexto, pasaré a identificar los siguientes instrumentos internacionales ratificados por el Estado peruano que protegen los derechos fundamentales de este grupo vulnerable:

Para mayor detalle, resulta interesante transcribir los artículos $4^{\circ}, 5^{\circ}, 6^{\circ} \mathrm{y}$ $8^{\circ}$ del "Protocolo Facultativo de la Convención sobre los Derechos del Niño relativo a la participación de los niños en conflictos armados" 3

\section{Artículo $4^{\circ}$}

1. Los grupos armados distintos de las fuerzas armadas de un Estado no deben en ninguna circunstancia reclutar o utilizar en hostilidades a menores de 18 años.

2. Los Estados Partes adoptarán todas las medidas posibles para impedir ese reclutamiento y utilización, con inclusión de la adopción de las medidas legales necesarias para prohibir y tipificar esas prácticas.

3. La aplicación del presente Artículo no afectará la situación jurídica de ninguna de las partes en un conflicto armado.

\section{Artículo $6^{\circ}$}

1. Cada Estado Parte adoptará todas las medidas jurídicas, administrativas y de otra índole necesarias para garantizar la aplicación efectiva y la vigilancia del cumplimiento efectivo de las disposiciones del presente Protocolo dentro de su jurisdicción.

\footnotetext{
3 Aprobado por Resolución Legislativa $N^{\circ} 27518$ de fecha 13 de setiembre de 2001. Ratificado por Decreto Supremo $N^{\circ}$ 078-2001, el 04 de octubre de 2001. Entró en vigencia el 12 de febrero de 2002.
} 
2. Los Estados Partes se comprometen a difundir y promover por los medios adecuados, entre adultos y niños por igual, los principios y disposiciones del presente Protocolo.

3. Los Estados Partes adoptarán todas las medidas posibles para que las personas que estén bajo su jurisdicción y hayan sido reclutadas o utilizadas en hostilidades en contradicción con el presente Protocolo sean desmovilizadas o separadas del servicio de otro modo. De ser necesario, los Estados Partes prestarán a esas personas toda la asistencia conveniente para su recuperación fisica y psicológica y su reintegración social.

\section{Artículo 7}

1. Los Estados Partes cooperarán en la aplicación del presente Protocolo, en particular en la prevención de cualquier actividad contraria al mismo y la rehabilitación y reintegración social de las personas que sean víctimas de actos contrarios al presente Protocolo, entre otras cosas mediante la cooperación técnica y la asistencia financiera. Esa asistencia y esa cooperación se llevaráa cabo en consulta con los Estados Partes afectados y las organizaciones internacionales pertinentes".

Como se puede observar, de los citados artículos se esgrime que los Estados Parte deben adoptar todas las medidas necesarias para evitar el reclutamiento de menores de 18 años. Ahora bien, teniendo en cuenta que el legislador peruano tiene la obligación de emitir las leyes y los actos necesarios para conseguir los fines indicados, en nuestra actual normatividad interna se identifica lo siguiente:

\begin{tabular}{|c|c|}
\hline $\begin{array}{c}\text { Constitución } \\
\text { Política } \\
\text { del Perú } \\
\mathbf{( 1 9 9 3 )}\end{array}$ & $\begin{array}{c}\text { Artículo } 4^{\circ} \text { " "La comunidad y el Estado protegen especialmente al niño, al adolescente, a la } \\
\text { madre y al anciano en situación de abandono (...)". }\end{array}$ \\
\hline $\begin{array}{c}\text { Código del } \\
\text { Niño y } \\
\begin{array}{c}\text { Adolescente- } \\
\text { Ley } \mathbf{N}^{\circ} \mathbf{2 7 3 3 7}\end{array}\end{array}$ & $\begin{array}{c}\text { "Artículo } 4^{\circ} \text { - A su integridad personal } \\
\text { El niño y el adolescente tienen derecho a que se respete su integridad moral, psiquica y } \\
\text { o degradante. Se consideran formas extremas que afectan su integridad personal, el trabajo } \\
\text { forzado y la explotación económica, así como el reclutamiento forzado, la prostitución, la } \\
\text { trata, la venta y el tráfico de niños y adolescentes y todas las demás formas de explotación". }\end{array}$ \\
\hline $\begin{array}{c}\text { Código Penal } \\
\text { peruano- } \\
\text { Decreto } \\
\text { Legislativo } \\
\mathbf{N}^{\circ} \mathbf{6 3 5}\end{array}$ & Este delito no se encuentra tipificado. \\
\hline
\end{tabular}


Es de notar que las disposiciones internacionales que protegen a los menores víctimas de reclutamiento no tienen un debido correlato en nuestro ordenamiento jurídico interno debido principalmente a:

Ausencia de tipificación de este acto como delito en nuestro Código Penal.

- Ausencia de implementación de programas especiales de protección para todos los casos de niñas, niños y adolescentes víctimas de reclutamiento en el Código del Niño y Adolescente.

Ahora bien, respecto a la ausencia de tipificación de este acto como delito en nuestro código penal, es pertinente en primer lugar identificar los derechos fundamentales vulnerados:

E Hereeho a la vida.

Articulo $2^{\circ}$ inc 1 de 1 Constitueion Politica del Pert

Ariculo $1^{\circ}$ del Codigo del Niño y Adolescente

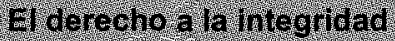
peisenal

Articulo $2^{\circ}$ inc.1 de 1 a Constiticion Polltica del Pert.

Articulo $4^{\circ}$ del Codigo del Nino y Adolescente
Ederceho a r liveriad

iculo $2^{\circ}$ inc. 24 de la Constitución Politica del Peru

Articulo $5^{\circ}$ del Codigo de Nino y Adolescente

En relación a estos derechos, el artículo VII del Título Preliminar de nuestro Código del Niño y Adolescente (CNA), establece que:

"En la interpretación y aplicación del presente Código se tendrá en cuenta los principios y las disposiciones de la Constitución Política del Perú, la Convención sobre los Derechos del Niño y de los demás convenios internacionales ratificados por el Perú. En todo lo relacionado con los niños y adolescentes, las instituciones familiares se rigen por lo dispuesto en el presente Código y el Código Civil en lo que les fuere aplicable".

Es decir, nuestro Código del Niño y del Adolescente se interpreta según los tratados de derechos humanos que hemos ratificado. Entonces, toda interpretación que se haga de este cuerpo normativo debe reflejarse al momento de legislar.

Teniendo en cuenta los derechos vulnerados y el artículo VII del Título Preliminar del CNA, podemos observar el por qué se suele asociar este delito con los siguientes tipos penales de nuestra legislación penal: 
- Decreto Ley No 25475 - "Establecen la penalidad para los delitos de terrorismo y los procedimientos para la investigación, la instrucción y el juicio": Artículo $3^{\circ}$, literal c) segundo párrafo y artículo 6-A.

- Decreto Legislativo N 635- Código Penal- "Delito de Secuestro": Artículo $152^{\circ}$-inc. $8^{\circ}$.

- Decreto Legislativo N 635- Código Penal- "Delito de Exposición o Abandono Peligroso": Artículo $125^{\circ}$.

- Decreto Legislativo N 635- Código Penal- "Delito de Exposición o Abandono Peligroso": Artículo $153^{\circ}$-A.

Si bien las cuatro fórmulas legales contemplan la protección de los derechos fundamentales antes citadas, del estudio de nuestro bloque de constitucionalidad se desprende que el Estado debe tipificar este delito en su derecho penal doméstico, satisfaciendo los estándares internacionales; es decir, se debe reflejar la gravedad y seriedad de estas acciones tomando criterios de derecho internacional.

En relación al tema, es preciso ahondar sobre el Decreto Ley $\mathrm{N}^{\circ} 25475$, "Ley que establece la penalidad para los delitos de terrorismo y los procedimientos para la investigación, la instrucción y el juicio", que tipifica el reclutamiento de menores de edad para facilitar actos terroristas.

Como podemos observar, esta Ley se circunscribe a la comisión de" actos terroristas" definidos en su artículo $2^{\circ}$, de la siguiente manera:

"El que provoca, crea o mantiene un estado de zozobra, alarma o temor en la población o en un sector de ella, realiza actos contra la vida, el cuerpo, la salud, la libertad y seguridad personales o contra el patrimonio, contra la seguridad de los edificios públicos, vías o medios de comunicación o de transporte de cualquier indole, torres de energía o transmisión, instalaciones motrices o cualquier otro bien o servicio, empleando armamentos, materias o artefactos explosivos o cualquier otro medio capaz de causar estragos o grave perturbación de la tranquilidad pública o afectar las relaciones internacionales o la seguridad de la sociedad y del Estado, será reprimido con pena privativa de libertad no menor de veinte años".

Es decir, en caso de producirse el reclutamiento de menores con otro tipo de fines, como por ejemplo, por adoctrinamiento, servicio de cocineros, mensajeros, etc.; no podría ser encuadrado en este tipo penal, a pesar de que en esas circunstancias se encuentran indudablemente en peligro de ser un potencial objetivo de ataque. 
En ese orden de ideas, nuestra actual legislación penal es insuficiente.

Esta constatación sumada al hecho de que existen instrumentos jurídicos internacionales que lo prohíben categóricamente justifica la incorporación de un tipo penal autónomo en nuestra legislación penal nacional que no invisibilice sus causas y tome sus características propias evitando vacíos legales en los que se amparen nuevas formas de subvertir el orden democrático constitucional.

Por otro lado, respecto a la obligación de implementación de programas especiales de protección para todos los casos de niños y adolescentes víctimas de reclutamiento en el Código del Niño y Adolescente, que emana del artículo $7^{\circ}$ del Protocolo Facultativo de la Convención de los Derechos del Niño relativo a la participación de niños en conflictos armados, si bien desde el Gobierno se están trabajando líneas de acción importantes para la protección de los niños y adolescentes; no se han formado programas especiales, ni un protocolo de protección integral que les brinde asistencia conveniente para su recuperación física, psíquica y su plena reinserción social acorde al Objetivo Estratégico $N^{\circ} 23$ del Plan Nacional de Acción por la Infancia y Adolescencia (PNAIA 2012-2021), aprobado por Decreto Supremo $\mathrm{N}^{\circ} 001-2012-\mathrm{MIMP}^{4}{ }^{4}$

Incluso el "Programa de Intervención Multisectorial del Gobierno Central en el VRAEM 2013-2016"5, que tiene como objetivo lograr un entorno de seguridad, legalidad y paz social no tiene entre sus ejes de intervención y acciones a realizar, ni la prevención del reclutamiento de niños y adolescentes ni la facilitación de su reinserción.

Un desarrollo importante sobre el tema, por ejemplo, está siendo ejecutado por el Instituto de Bienestar Familiar del Estado colombiano a través del "Programa de Prevención para el Reclutamiento y Uso de Niños, Niñas y

\footnotetext{
4 Resultado Esperado 23: Niñas, niños y adolescentes no participan en conflictos internos

Meta:

No hay niña, niño o adolescente participando voluntariamente o por la fuerza en conflictos internos en el país.

Indicador: Número de niñas, niños o adolescentes participando voluntariamente o por la fuerza en conflictos internos en el país.

Estrategias de implementación

-Priorizar el rescate de las niñas, niños y adolescentes en poder de grupos al margen de la ley.

- Desarrollar campañas de comunicación y educación en los departamentos y comunidades afectadas por grupos al margen de la ley u organizaciones criminales dedicadas al narcotráfico y otros delitos, a fin de evitar que las niñas, niños y adolescentes sean reclutados e incorporados a dichas cadenas delictivas.

5 Aprobado por Decreto Supremo Nº77-2013-PCM el 26 de junio de 2013.
} 
Adolescentes por los Grupos Armados Organizados al Margen de la Ley y de Atención, Seguimiento y Acompañamiento a los Desvinculados"6. Este programa tiene varios componentes, que en nuestro contexto también sería necesario poner en práctica, éstos son:

- Componente de Salud y Nutrición

- Componente Psicosocial

- Componente Pedagógico

- Componente Cultural y de Convivencia

- Componente Familiar

En esa misma línea, es importante tratar a esta problemática con las características propias que posee y no como modalidad del delito de Trata de Personas, como lo ha ido trabajando el Ministerio del Interior (MININTER) en su Plan Nacional de Acción contra la Trata de Personas (PNAT 2011-2016), ya que su trabajo podría llegar a ser ineficaz, al no figurar el reclutamiento de menores como modalidad de trata de personas en nuestro Código Penal.

En referencia a ello, cabe señalar que si bien la inclusión de este supuesto es justificado por el PNAT argumentándose que" debe adoptarse un prisma amplio en la defensa de los derechos humanos"; sin embargo, a criterio de la Defensoría del Pueblo, se contravendría al principio de legalidad, toda vez que a través de una norma reglamentaria no se debe ampliar una norma con rango de ley. ${ }^{7}$

\section{Obligaciones Internacionales en Materia de Implementación de Tratados de Derechos Humanos}

El derecho internacional no prescribe una técnica determinada de incorporación de las normas internacionales en los ordenamientos internos ni la autoridad que estas tendrán en relación con la legislación interna. El derecho internacional, impone a los Estados una obligación de resultado que se enuncia en la fórmula pacta sunt servanda, por ello, la elección de los medios con que se haga efectiva esta obligación les corresponde a cada Estado.

\footnotetext{
6 Http://www.oim.org.co/.../211-guia-para-el-restablecimiento-integral-de-derechos-de-ninos-ninas-adolescentes-yjovenes-desvinculados-de-grupos-armados-organizados-al-margen-de-la-ley-pdf

${ }^{7}$ Http://www.defensoria.gob.pe/Downloads/informes/defensoriales/Informe-Defensorial-158.pdf
} 
Sin embargo, en el ámbito de los derechos humanos esta obligación resulta incluso más determinante tal como lo expresan los tratados internacionales, la jurisprudencia y la doctrina en este campo. Por ejemplo, de acuerdo con el artículo $1^{\circ}$ inciso 1 de la Convención Americana sobre Derechos Humanos, el Estado tiene la obligación de respetar los derechos fundamentales y de garantizar su libre y pleno ejercicio a toda persona que esté sujeta a su jurisdicción, sin discriminación alguna.

Esta referencia a la Convención resulta de singular importancia, en tanto que nuestra Constitución Política no presenta una norma muy clara y precisa sobre el tema; ya que si bien su artículo $44^{\circ}$ dispone la obligación del Estado de garantizar la plena vigencia de los derechos humanos, el texto de la Convención Americana es más claro y directo al señalar estas obligaciones de cumplimiento.

La "obligación de cumplimiento" en materia de derechos humanos se manifiesta según el doctor $\mathrm{Nash}^{8}$, a través de dos obligaciones principales: respeto y garantía de los derechos y libertades consagrados internacionalmente, cualquiera sea el tipo de documento en el que se consagre, en conjunto con el principio de igualdad y no discriminación.


Cumplir directamente con la conducta establecida en cada norma internacional, ya sea absteniéndose de actuar o dando una prestación.

Entre las medidas que debe adoptar el Estado, tenemos las acciones de cumplimiento: positivas (implica una actividad de prestación) o negativas (implica una actividad de abstención).

Se traduce en la obligación del Estado de crear condiciones efectivas de goce y ejercicio de los derechos consagrados en los instrumentos internacionales a través de:

${ }^{8}$ Nash Rojas,Claudio. Op. Cit.p. 32 
- Medidas positivas

- Obligación de investigar

- Reparación a las víctimas

- Obligación de sancionar

- Cooperación con los órganos internacionales para que estos puedan desarrollar sus actividades de control

En el derecho internacional se ha desarrollado un acervo normativo y jurisprudencial relevante sobre derechos humanos que ha comenzado a impactar en los sistemas nacionales y que ha aportado nuevos elementos para el análisis de los temas centrales de los derechos fundamentales. Al respecto, el desarrollo jurisprudencial que de la Corte Interamericana de Derechos Humanos en relación a la eficacia de los derechos fundamentales entre los particulares, se ha reconocido la obligatoriedad de los derechos garantizados en los tratados de derechos humanos por parte de los particulares, constituyéndose así en un importante avance que no circunscribe la efectividad de los derechos fundamentales únicamente como un deber a realizar por los Estados.

En relación a ello, la Corte Interamericana en su sentencia del caso "Comunidad Indígena Sawhoyamaxa vs. Paraguay", analizando los alcances del derecho a la vida y las obligaciones positivas del Estado, ha definido lo siguiente:

"El Estado debe adoptar todas las medidas apropiadas para proteger y preservar el derecho a la vida, conforme lo dispuesto en los artículos 4.1 y 1.1 de la Convención Americana de Derechos Humanos. Estas medidas apropiadas implican crear un marco normativo adecuado que disuada cualquier amenaza al derecho a la vida; establecer un sistema de justicia efectivo y capaz de investigar y reparar toda privación de la vida por parte de agentes estatales o particulares; $y$ salvaguardar el derecho a que no se impida el acceso a las condiciones que garanticen una vida digna, lo que incluye la adopción de medidas positivas para prevenir la violación de este derecho" ${ }^{9}{ }^{9}$

Asimismo, a juicio de la Corte en la Sentencia anteriormente citada, existen límites para que el Estado incurra en violación de esta obligación de garantía:

\footnotetext{
9 Corte Interamericana de Derechos Humanos. Sentencia del caso "Comunidad Indígena Sawhoyamaxa vs. Paraguay", emitida el 29 de marzo de 2006. Punto 153.
} 
"Es claro para la Corte que un Estado no puede ser responsable por cualquier situación de riesgo al derecho a la vida (...). Para que surja esta obligación positiva, debe establecerse que al momento de los hechos las autoridades sabian o debian saber de la existencia de una situación de riesgo real e inmediato para la vida de un individuo o grupo de individuos determinados, y no tomaron las medidas necesarios dentro del ámbito de sus atribuciones que, juzgadas razonablemente, podian esperarse para preveniroevitar ese riesgo ${ }^{\prime 10}$

Tomando en cuenta ello, el Estado tiene la obligación de proteger a las personas frente a la amenaza de sus derechos ya sea por agentes del Estado o por privados. En ese sentido, se deben adoptar las medidas adecuadas, sean normativas $u$ organizacionales, para enfrentar casos de amenazas a los derechos garantizados internacionalmente toda vez que la obligación de protección no se cumple con la adopción de medias genéricas sino con medidas particulares que miren la concreta situación del titular de derechos. Por lo tanto, los remanentes de Sendero Luminoso que están empleando a niños y adolescentes en los enfrentamientos armados o en labores vinculadas a éstas, no se encuentran exentos de la infracción de las normas de los tratados de derechos humanos. La concepción de que sólo el Estado se constituye como responsable de violaciones al Derecho internacional de Derechos Humanos es un tema que se encuentra superado por el propio desarrollo y la búsqueda de lograr su mayor efectividad del Derecho internacional de los Derechos Humanos.

Así, por ejemplo, el doctor Gómez Robledo, señala que los actos de particulares que implican una violación de derechos humanos devienen en actos públicos, pues en su opinión:

"(...) se puede decir que el Estado está 'endosando', por su propio comportamiento de sus nacionales, que en un principio, no eran sino simples particulares, sin mayor conexión con el aparato gubernamental del Estado; el acto 'privado' deviene 'público' y por lo tanto, susceptible de imputación al Estado".

En relación a lo antes dicho, por ejemplo, la Corte Interamericana en el caso "Paniagua Morales y otros vs. Guatemala"11, reiteró la Responsabilidad Internacional del Estado guatemalteco en virtud de su tolerancia para con los hechos ilícitos violatorios de derechos humanos, así como por su negligencia

\footnotetext{
10 Ibíd. Punto 152.

11 Corte Interamericana de Derechos Humanos. Sentencia del caso "Paniagua Morales y otros vs. Guatemala", emitida el 08 de marzo de 1998.
} 
para investigar y sancionar a los responsables, considerando que la omisión del Estado, tiene su origen en la imposibilidad de garantizar a las víctimas el pleno ejercicio de sus derechos humanos.

Por otro lado, también se comprometería la Responsabilidad Internacional de un Estado cuando no adopta disposiciones legislativas necesarias para compatibilizar su legislación con las obligaciones internacionales. Ello fue señalado en la sentencia de la Corte Interamericana en el Caso "La última tentación de Cristo vs. Chile"12, ya que entre sus argumentos señalan "cuando los Estados ratifican un tratado y lo hacen parte de su legislación, se están comprometiendo también a adecuar toda su legislación interna de acuerdo a los estándares del tratado internacional y en ese sentido el esfuerzo que deben llevar los Estados es ver cómo el conjunto de su cuerpo normativo y las prácticas que de él emanen se ajustan a las obligaciones que están adquiriendo".

En ese mismo tenor se pronuncia el Comité de Derechos Humanos, en su Observación General N 31, al señalar que "puede haber circunstancias en las que, por no haberse garantizado los derechos reconocidos en el Pacto como se dispone en el artículo 2, los Estados parte infrinjan estos derechos permitiendo a particulares $o$ entidades que cometan tales actos o no adoptando las medidas apropiadas o no ejerciendo el cuidado debido para prevenir, castigar, investigar o reparar el daño así causado" ${ }^{13}$

Entonces, el Perú al incumplir sus obligaciones internacionales de protección a los niños y adolescentes víctimas de reclutamiento, puede incurrir en responsabilidad internacional por tres aspectos sustanciales: primero, la imposibilidad estatal de impedir que semejantes hechos tengan lugar; segundo, su fracaso en encontrar a los criminales e imponer las penas correspondientes; $y$, tercero, la falta de un adecuado programa de rehabilitación para las víctimas.

En el primer supuesto, la responsabilidad por omisión tendría su origen en la ineficiencia en el tratamiento jurídico del caso VRAEM, donde se ha constatado claramente una cadena de mando y la capacidad de reclutar a menores de edad; en el segundo supuesto, la responsabilidad nacería tanto

\footnotetext{
12 Corte Interamericana de Derechos Humanos. Sentencia del caso "La última tentación de Cristo vs. Chile", emitida el 05 de febrero de 2001 .

${ }^{13}$ http://www1.umn.edu/humanrts/hrcommittee/Sgencom31.html
} 
del insuficiente actuar de la administración de justicia (básicamente Ministerio Público y Poder Judicial) como de la omisión de producción legislativa referente al tema; y finalmente, el tercer supuesto derivaría de la falta de políticas públicas específicas referentes al tema.

\section{Conclusión}

Todo sistema constitucional eficiente de un Estado debe estar en las posibilidades de garantizar a la población el goce y disfrute de sus derechos fundamentales siendo éstos la fuente de legitimidad; por ello, el reclutamiento de niños y adolescentes en la zona VRAEM por remanentes de Sendero Luminoso representa una vulneración a sus derechos fundamentales. La carencia de un adecuado desarrollo constitucional en la materia generaría en el peor de los escenarios, la posible imputación de responsabilidad internacional al Estado peruano.

Este esfuerzo por comprender la especial situación vivida en el VRAEM por nuestros menores sería estéril si no trae consigo la reflexión. El desafío está en actuar siempre considerando que los derechos humanos no pueden ser abordados exclusivamente por el derecho internacional ni por el derecho constitucional, sino por un método multidisciplinario que permitan garantizar sus derechos.

Manos a la obra.

\section{Referencias}

- Toche Medrano, Eduardo. (2010) "Los Niños de la Guerra". En Revista Ideele, edición Nº180. Lima-Perú.

- Novak, Fabián \& Namihas, Sandra \& García Corrochano, Luis \& Huamán, Milagros. (2011) "Niños, niñas y adolescentes en las zonas cocaleras del VRAE y el Alto Huallaga". En Editorial Instituto de Estudios Internacionales (IDEI). Primera Edición- Pontificia Universidad Católica del Perú.

- Nash Rojas, Claudio. (2011) "Relación entre el sistema constitucional e internacional de los derechos humanos". En Revista sobre cultura, democracia y derechos humanos del Instituto de Derechos Humanos de la PUCP. 
- Instituto Colombiano de Bienestar Familiar. (setiembre 2008) "Guía para el restablecimiento integral de derechos de los niños, niñas, adolescentes y jóvenes desvinculados de los grupos armados organizados al margen de la Ley".

Disponible en Internet://www.oim.org.co/.../211-guia-para-elrestablecimiento-integral-de-derechos-de-ninos-ninas-adolescentes-yjovenes-desvinculados-de-grupos-armados-organizados-al-margen-dela-ley.pdf. p. 24-26. Consultado el 25 de abril de 2014.

- Defensoría del Pueblo. "La trata de personas en agravio de niños y adolescentes". Serie de Informes Defensoriales-Informe N 158.

Disponible en Internet:

http://www.defensoria.gob.pe/modules/Downloads/informes/ defensoriales/Informe-Defensorial-158.pdf. p. 49. Consultado el 10 de mayo de 2014.

Corte Interamericana de Derechos Humanos. Sentencia del caso "Comunidad Indígena Sawhoyamaxa vs. Paraguay, emitida el 29 de marzo de 2006. Punto 152 y 153.

Disponible en Internet:

http://www.corteidh.or.cr/docs/casos/articulos/seriec_146_esp2. pdf.Consultado el 07 de junio de 2014.

- Corte Interamericana de Derechos Humanos. Sentencia del caso "Caso de la "Panel Blanca" (Paniagua Morales y otros) vs. Guatemala" emitida el 08 de marzo de 1998.

Disponible en Internet:

http://www.corteidh.or.cr/docs/casos/articulos/seriec_37_ esp.pdf. Consultado el 07 de junio de 2014.

- Corte Interamericana de Derechos Humanos. Sentencia del caso "La última tentación de Cristo vs. Chile" emitida el 05 de febrero de 2001.

Disponible en Internet:

file:/ / D:/Mis\%20documentos/Downloads/Caso\%20Ultima\% 20 Tentacion\%20de\%20Cristo.Consultado el 07 de junio de 2014 .

- Observación General No. 31. (2004) Comentarios generales adoptados por el Comité de los Derechos Humanos. La índole de la obligación jurídica general impuesta, $80^{\circ}$ período de sesiones, U.N. Doc. HRI/GEN/1/Rev.7 at 225 (2004).

Disponible en Internet:

http://www1.umn.edu/humanrts/hrcommittee/Sgencom31.html. Consultado el 07 de junio de 2014. 